\title{
Leukemic Phase of Intermediate Non-Hodgkin's Lymphoma with Cells Showing Different Matured Stages in Invaded Various Organs
}

\author{
Takashi Shimamoto, Kazuma Ohyashiki, Yoshio Nehashi, Tetsuzo Tauchi, Junko H. Ohyashiki \\ and Keisuke TOYAMA
}

\begin{abstract}
A 56-year-old male was admitted to our hospital with lymphocytosis $\left(16.4 \times 10^{9} / 1 ; 79 \%\right.$ lymphocytes including 50\% small lymphocytes), generalized lymphadenopathy, massive splenomegaly, and heavily infiltrated bone marrow. Immunophenotype analysis of the neoplastic cells in the bone marrow revealed that they were $\mathrm{B}$ cells $(\mathrm{CD20}+\mathrm{CD19}+\mathrm{Ia} 1+\mathrm{sIgM}+)$ positive for CD10. By contrast, the cells in the lymph node were CD20+CD19+Ia1+sIgM+ but negative for CD10. The patient was tentatively diagnosed as having lymphosarcoma cell lymphoma, however, the final diagnosis was leukemic phase of intermediate lymphocytic lymphoma. We concluded that CD10 + neoplastic cells in the bone marrow and peripheral blood had differentiated to $\mathrm{CD10}$ - cells.
\end{abstract}

(Internal Medicine 31: 553-556, 1992)

Key words: B-cell neoplasia, intermediate lymphocytic lymphoma

\section{Introduction}

The disease entity of lymphoproliferative disorders includes chronic lymphocytic leukemia (CLL) and nonHodgkin's lymphoma (NHL) (1-4). The utilization of cell surface marker analysis has made it possible to identify not only cellular ontogeny but also the maturation stage of normal counterparts of lymphocytes $(5,6)$. In some patients with B cell type lymphoproliferative disorder, the differential diagnosis between CLL and NHL in the leukemic phase is difficult, even when the surface markers of neoplastic cells are analyzed.

We report a case with clinical findings involving central nervous system and cytological features of the circulating cells compatible with so-called lymphosarcoma cell leukemia (LSCL). The maturation level of neoplastic cells in the bone marrow (BM) and peripheral blood (PB) was different from that in the lymph node and cerebrospinal fluid (SCF), indicating that the unusual clinical manifestation was due to the unique characteristics of the neoplastic cells with CD10 antigen.

\section{Case Report}

A 56-year-old male complained of lumbago in October 1986 and was admitted to our hospital in December 1986. Physical examination on admission revealed a massive splenomegaly and mild hepatomegaly $(20 \mathrm{~cm}$ and $2 \mathrm{~cm}$ below costal margin). Generalized lymphadenopathy was also noted in the cervical, axillary, and inguinal regions. The leukocyte count was $16.4 \times 10^{9} / 1$, including $79 \%$ lymphocytes (Table 1); about $50 \%$ of which resembled mature small lymphocytes, but their chromatin patterns were somewhat fine compared to those of normal mature lymphocytes. The remaining $50 \%$ had relatively large nuclei with a fine chromatin pattern, and prominent nucleoli (Fig. 1A). The nuclear contour of the later cells was occasionally clefted and folded, and they had irregular cytoplasmic projections. Bone marrow examination revealed a nucleated cell count of $284 \times 10^{9} / 1$, including $78.8 \%$ lymphocytes without prominent nucleoli, but some of them had indented nuclei (Fig. 1B). The neoplastic cells in the BM were $\mathrm{CD} 20+\mathrm{CD} 19+\mathrm{Ia} 1+\mathrm{sIgM}+\mathrm{CD} 10+$ by flowcytometric analysis (Table 2). Biopsy of the inguinal lymph node

From the First Department of Internal Medicine, Tokyo Medical College, Tokyo

Received for publication June 14, 1991; Accepted for publication December 17, 1991

Reprint requests should be addressed to Dr. Takashi Shimamoto, the First Department of Internal Medicine, Tokyo Medical College, 6-7-1 Nishishinjuku, Shinjuku-ku, Tokyo 160, Japan 
Table 1. Hematological Findings on Admission

\begin{tabular}{lrlr}
\hline $\begin{array}{l}\text { Peripheral blood } \\
\text { Leukocytes }\end{array}$ & $16.4 \times 10^{9} / 1$ & Bone marrow & Nucleated cell counts \\
Stab cells & $4 \%$ & Megakaryocytes & $18.75 \times 10^{9} / 1$ \\
Segmental cells & $12 \%$ & ME ratio & $2.8: 1$ \\
Eosinophils & $2 \%$ & Myelogram & \\
Monocytes & $3 \%$ & Myeloid cells & $12.8 \%$ \\
Lymphocytes & $71 \%$ & Erythroid cells & $5.2 \%$ \\
Atypical lym. & $8 \%$ & Lymphoid cells & $81.6 \%$ \\
Red blood cells $3.66 \times 10^{12} / 1$ & Mature lymphocytes & $78.8 \%$ \\
Hemoglobin & $115 \mathrm{~g} / 1$ & Blastoid lymphocytes & $2.8 \%$ \\
Hematocrit & $34.0 \%$ & & \\
Platelets & $126 \times 10^{9} / 1$ & & \\
\hline
\end{tabular}

demonstrated a diffuse infiltration composed of small lymphocytic cells (Fig. 2). The pathological diagnosis was diffuse and small cleaved NHL, according to the working formulation of the Non-Hodgkin's Lymphoma Pathologic Classification. The neoplastic cells in the excised lymph node had CD20+CD19+Ia1+sIgM+ (lambda chain) but were negative for CD10 (Table 2). Monoclonal gammopathy was not detected.

The patient was given four courses of CHOP therapy (cyclophosphamide, doxorubicin, vincristine, and prednisolone). In May 1987, splenomegaly and lymphadenopathy had disappeared, however, the BM was still heavily
Table 2. Surface Marker Analysis (Percent Positive) on Admission

\begin{tabular}{llrrrc}
\hline & CD & $\begin{array}{c}\text { Peripheral } \\
\text { blood }\end{array}$ & $\begin{array}{c}\text { Bone } \\
\text { marrow }\end{array}$ & $\begin{array}{c}\text { Lymph } \\
\text { node }\end{array}$ & $\begin{array}{c}\text { Cerebrospinal } \\
\text { fluid }\end{array}$ \\
\hline OKT3 & CD3 & 15.0 & 17.1 & 15.6 & 2.1 \\
OKT4 & CD4 & 11.8 & 8.8 & 12.0 & $<1.0$ \\
OKT8 & CD8 & 5.4 & 5.9 & 15.0 & 2.9 \\
OKT10 & CD38 & 68.4 & 86.6 & 29.8 & ND \\
Ia1 & & 88.4 & 88.6 & 75.5 & 99.5 \\
B1 & CD20 & 83.2 & 83.0 & 62.5 & 98.1 \\
B2 & CD21 & 17.5 & 12.6 & 49.5 & 8.6 \\
B4 & CD19 & 84.0 & 85.6 & 60.3 & 97.9 \\
HLA-DR & 85.4 & ND & 87.9 & ND \\
J5 & CD10 & 23.0 & 76.8 & 5.2 & 15.6 \\
sIg (total) & 85.4 & 87.0 & 85.0 & 96.4 \\
IgG & & 1.0 & ND & 11.6 & 66.9 \\
IgA & & 1.5 & ND & 7.0 & 52.9 \\
IgM & & 82.9 & ND & 81.5 & 97.3 \\
IgD & & 23.4 & ND & 11.4 & 36.4 \\
Ig $K$ & & 2.3 & ND & 5.7 & 25.5 \\
Ig $\lambda$ & & 79.6 & ND & 82.8 & 80.7 \\
\hline
\end{tabular}

CD: cluster designation, ND: not done.

infiltrated with small lymphocytes $(75.6 \%)$ and the circulating lymphocytes count remained high. Because the patient's status was generally improved and the hematologic conditions were not progressive, he was followed
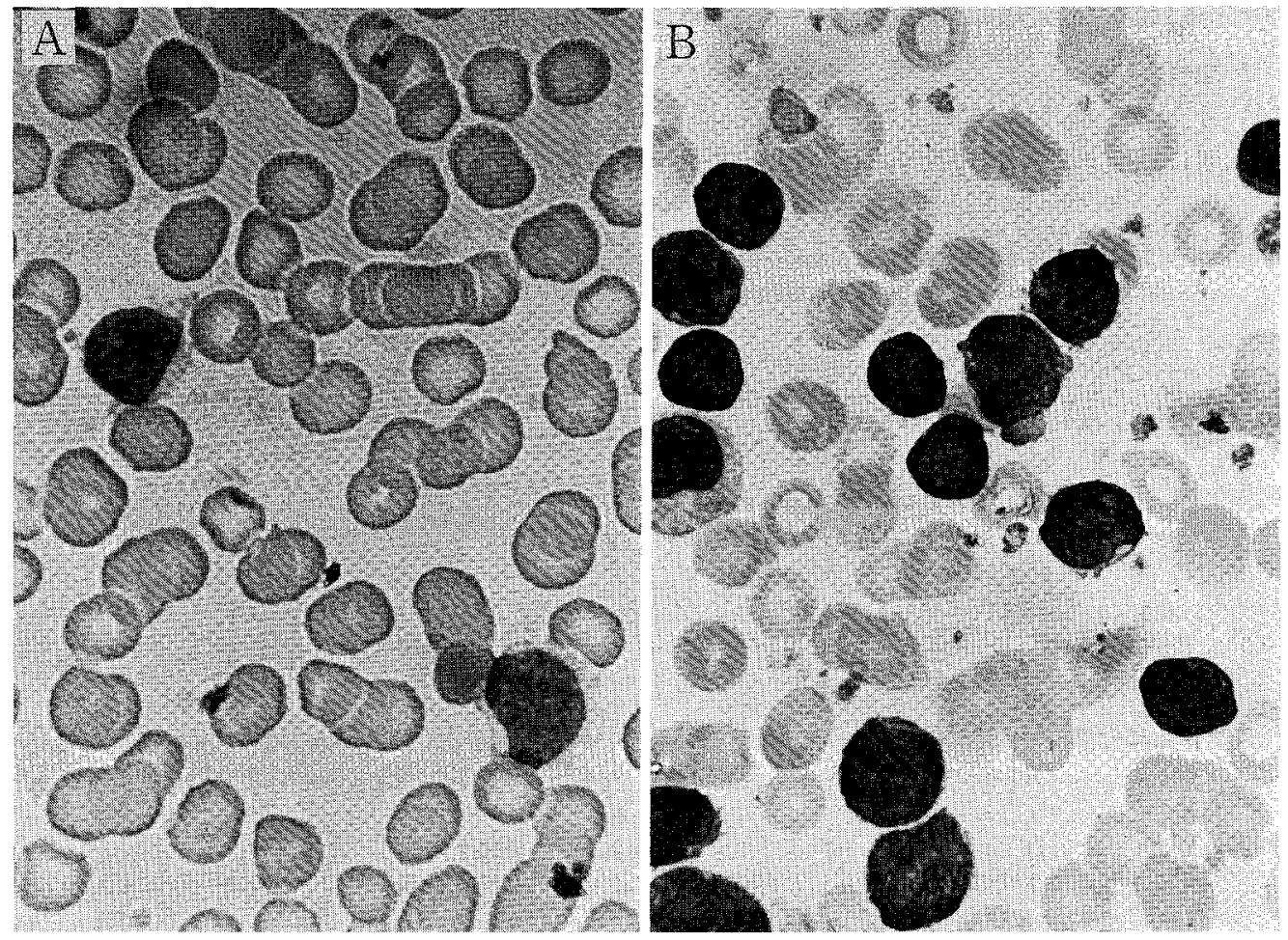

Fig. 1. A) Photomicrogram obtained from the peripheral blood on admission. The circulating cells were similar to mature small lymphocyte in size, and containcd large nuclei with irregular cytoplasmic contours. They have a relatively fine chromatin pattern and prominent nucleoli (May-Grünwald-Giemsa stain, $\times 800$ ). B) A representative photomicrogram of the infiltrated cells in the bone marrow. The neoplastic cells did not have apparent nuclcoli; some cells had indented nuclci (May-Grünwald-Giemsa stain, $\times 800$ ). 


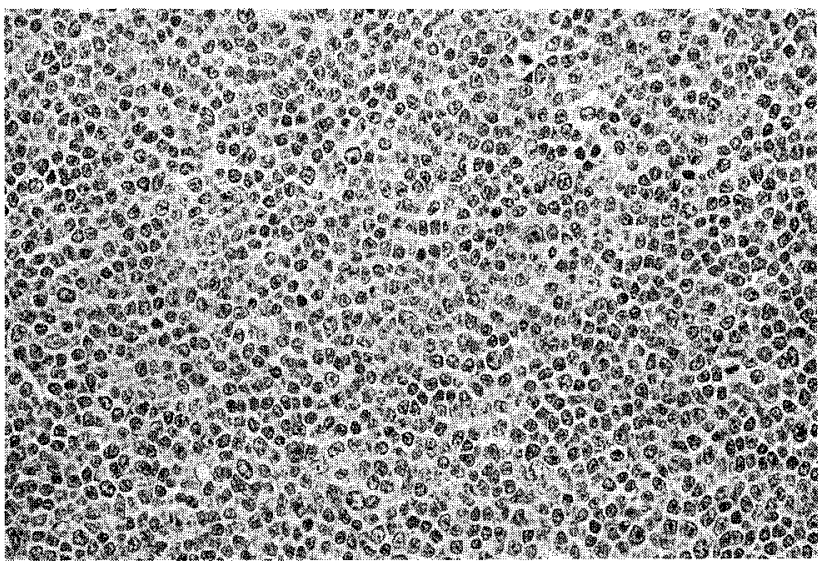

Fig. 2. Photomicrogram of the excised lymph node. Histological findings of the right inguinal lymph node biopsy specimen demonstrated a diffuse neoplastic lesion composed of small lymphocytic cells (hematoxylin-eosin stain, $\times 400$ ).

up as an out-patient and treated with intermittent oral cyclophosphamide $(100 \mathrm{mg} /$ day $)$.

In May 1988, the patient again manifested splenomegaly $(10 \mathrm{~cm}$ below the costal margin) with generalized lymphadenopathy and was readmitted. Bone marrow aspiration revealed lymphocytic infiltration and an ultrasonogram demonstrated intra-abdominal lymphadenopathy. Thus, the patient was again treated with CHOP therapy and this regimen was effective. However, the patient complained of neurologic symptoms, including a tingling sensation in both lower extremities, headache, and nausea. A spinal tap revealed lymphocytic infiltration of more than $1 \times 10^{9} / 1$ : the neoplastic cells were CD20+ CD19+Ia1+sIgM+CD10- (Table 2). Although the patient was treated with intrathecal methotrexate injection (15 mg, 8 times), cytosine arabinoside (20 mg, 6 times), and skull irradiation with generalized chemotherapy, optic and facial nerve palsy appeared. These treatments were partially effective in cytoreduction, however, the patient died of sepsis on February 6, 1989.

\section{Discussion}

Chronic lymphocytic leukemia and NHL in the leukemic phase are included in lymphoproliferative disorders, and patients with these two neoplastic forms sometimes exhibit similar clinical features $(1-4)$. Therefore, the differential diagnosis of these two neoplasias remains controversial. On the other hand, LSCL has been frequently used and encompasses a variant form of CLL in European and American reports (7-9), presenting clinically without lymphoma with a poorer prognosis than those with typical CLL (8). Recently, however, the trend has been to abolish this diagnosis in the classification of lymphoma to avoid confusion, and the entity of leukemic manifestation of NHL currently includes
LSCL (10).

We first thought that the patient suffered from CLL or NHL in the leukemic phase. However, the morphology of the neoplastic cells led us to consider the diagnosis of LSCL. First, the count of circulating lymphocytes on admission was very high $\left(13 \times 10^{9} / \mathrm{l}\right)$, but they had CD10 antigen with heterogenous morphologies. Second, the course of disease was relatively progressive with invasive nature. His general condition, including lymphadenopathy and splenomegaly, improved after chemotherapy, although the neoplastic cells remained in the BM and $\mathrm{PB}$ with high occurence rates. Finally, the morphology of neoplastic cells in the $\mathrm{PB}$ was different from those of typical CLL and those of leukemic manifestation of follicular lymphoma $(10,11)$ : some of the neoplastic cells in this case had nucleoli and clefted nuclei, but the clefts were not very narrow as those seen in the leukemic phase of follicular lymphoma. These clinical and cytologic features suggest the presence of the spectrum of chronic lymphoid leukemia consisting of CLL and leukemic NHL. Currently, the diagnosis of LSCL is considered to be included as the leukemic phase of intermediate or mantle zone (centrocytic) NHL $(12,13)$. The reason, however, that we hesitated to diagnose it as the leukemic phase of intermediate lymphocytic lymphoma is that the main lesion in this patient seemed to be $\mathrm{BM}$ and/or $\mathrm{PB}$, since after the first chemotherapy lymphadenopathy and splenomegaly disappered, whereas the $\mathrm{BM}$ infiltration abnormal cells in the PB remained.

Pombo de Oliveira et al (14) reported 16 patients with leukemic phase of mantle zone (intermediate) lymphoma, including 5 suspected cases, and none of the 16 cases manifested the massive splenomegaly likely in this case $(20 \mathrm{~cm})$ : most of them had splenomegaly less than $10 \mathrm{~cm}$ below costal margin (14). Nevertheless, the circulating lymphocytes reported by them resembled those presented here, therefore, the clinical viewpoint alone is insufficient to rule out the possible diagnosis of the leukemic phase of intermediate NHL; the most possible diagnosis for this patient might be the leukemic phase of intermediate NHL at this time.

In the present case, the neoplastic cells found in the $\mathrm{BM}, \mathrm{PB}, \mathrm{LN}$, and CSF might have originated from the same clone. The neoplastic cells in the LN expressing sIg, CD19, and CD20 without CD10 are considered to be more mature cells than those of BM (sIg + CD19+ $\mathrm{CD} 20+\mathrm{CD} 10+$ ). Thus, it is possible to consider that the CD10- cells in the PB migrated and expanded in the LN. The expression of CD10 in the neoplastic cells in the leukemic phase of intermediate NHL is controversial; the most likely interpretation is that the neoplastic cells in the $\mathrm{PB}$ have $\mathrm{CD} 10$ antigen by flowcytometric study $(12,13,15)$, however Weisenburger et al (11) failed to demonstrate CD10 reactivity by immunocytochemistry on frozen sections of LN. Pombo de Oliveira et al (14) described that circulating lymphocytes of all 16 cases had 


\section{Shimamoto et al}

CD5 antigen and 8 of 14 cases examined had CD10 antigen. Thus, it is uncertain whether the variety of CD10 expression in the neoplastic cells of leukemic phase of intermediate NHL that was reported previously might be attributable to the difference of techniques $(12,14)$ or it represents the nature of the disease (14), since the current case also showed the dissociation of CD10 expression between BM and LN. Therefore, detailed investigations of patients with $\mathrm{B}$-cell lymphoproliferative disease are needed to clarify their biological and hematological significance in the spectrum of B-cell type neoplasias.

\section{References}

1) Spiro S, Galton DAG, Wiltshaw E, Lohmann RC. Follicular Iymphoma: A survey of 75 cases with special references to the syndrome resembling chronic lymphocytic leukemia. Br J Cancer 31 (suppl II): 60, 1975.

2) Mathe G, Misset JL, Gil-Delgado M, Delgado M, DeVassal F. Leukemic (or stage V) lymphosarcoma. Recent Results Cancer Res 65: 88, 1977.

3) Pangalis G, Nathwani B, Rappaport H. Malignant lymphoma, well differenciated lymphocytic: Its relationship with chronic lymphocytic leukemia and macroglobulinemia of Waldenström. Cancer 39: 999, 1977.

4) Braylan R, Jaffe E, Burbach J, Frank M, Johnson R, Berard C. Similarities of surface characteristics of neoplastic well-differenciated lymphocytes from solid tissues and from peripheral blood. Cancer 36: 1619, 1976.

5) Sai JW, Pinkus GS. Immunologic characterization snd ultrastructual correlations for 125 cases of B- and T-cell leukemias:
Studies of chronic and acute lymphocytic, prolymphocytic lymphosarcoma cell and hairy cell leukemia, Sezary's syndrome and other lymphoid leukemias. Cancer 48: 2630, 1981.

6) Liebes L, Quagliata F, Silber R. The anomalous capping behavior of chronic lymphocytic leukemia lymphocytes: Studies with an antilymphocyte antiserum. Clin Immunol Immunopathol 10: 222, 1978.

7) Zacharski L, Linman J. Chronic lymphocytic leukemia versus chronic lymphosarcoma cell leukemia: Analysis of 496 cases. Am J Med 47: 75, 1969.

8) Mintzer DM, Hauptman SP. Lymphosarcoma cell leukemia and other non-Hodgkin's lymphomas in leukemic phase. Am J Med 75: 110, 1983.

9) Come SE, Jaffe ES, Anderson JC, et al. Non-Hodgkin's lymphomas in leukemic phase: Clinicopathologic correlations. Am J Med 69: 667, 1980.

10) Bennett JM, Catovsky D, Daniel M-T, et al. Proposals for the classification of chronic (mature) $\mathrm{B}$ and $\mathrm{T}$ lymphoid leukemias. J Clin Pathol 42: 567, 1989.

11) Weisenburger DD, Sanger WG, Armitage JO, Purtilo DT. Intermediate lymphocytic lymphoma: Immunophenotypic and cytogenetic findings. Blood 69: 1617, 1987.

12) Catovsky D, For R. The leukaemic phase of non-Hodgkin's lymphoma. in: The Lymphoid Leukaemias, Catovsky D, Ed. Butterworths, London, 1990, p. 182.

13) Cossman J, Neckers Lm, Hsu S-M, Longo D, Jaffe ES. Lowgrade lymphomas: Ëxpression of developmentalìy regulated B-cell antigens. Am J Pathol 115: 117, 1984.

14) Pombo de Oliveira MS, Jaffe MS, Catovsky D. Leukemic phase of mantle zone (intermediate) lymphoma: Its characterization in 11 cases. J Clin Pathol 42: 962, 1989.

15) Jaffe ES, Bookamn MA, Longo DL. Lymphocytic lymphoma of intermediate differentiation. Mantle zone lymphoma: A distinct subtype of B-cell lymphoma. Hum Pathol 18: 877, 1987. 